\title{
Desafios e possibilidades do serviço social no cenário educacional: revisão narrativa
}

\author{
Challenges and possibilities of social service in the educational scenario: narrative review \\ Retos y posibilidades del servicio social en el escenario educativo: revisión narrativa
}

Recebido: 22/10/2021 | Revisado: 30/10/2021 | Aceito: 30/10/2021 | Publicado: 01/11/2021

\author{
Wilson Fernandes de Lima \\ ORCID: https://orcid.org/0000-0002-5638-7780 \\ Universidade Pitágoras Unopar, Brasil \\ E-mail: wylson.fernandes@hotmail.com \\ Stefânia Vieira Rodrigues \\ ORCID: https://orcid.org/0000-0001-5744-5973 \\ Universidade Pitágoras Unopar, Brasil \\ E-mail: stefaniarodrigues14@hotmail.com \\ Joana de Moura e Silva \\ ORCID: https://orcid.org/0000-0002-6104-7991 \\ Instituto de Educação Superior Raimundo Sá, Brasil \\ E-mail: joanademoura@hotmail.com \\ Larissa Carvalho Martins \\ ORCID: https://orcid.org/0000-0002-7019-8724 \\ Instituto de Educação Superior Raimundo Sá, Brasil \\ E-mail: larissacarvalho0727@ hotmail.com \\ Ana Luiza Barbosa Negreiros \\ ORCID: https://orcid.org/0000-0002-8313-0403 \\ Universidade Federal do Piauí, Brasil \\ E-mail: analuiza.negreiros@ hotmail.com \\ Reijane da Rocha Silva \\ ORCID: https://orcid.org/0000-0002-1779-6442 \\ Universidade Pitágoras Unopar, Brasil \\ E-mail: reijaner69@gmail.com \\ Mayla Rosa Guimarães \\ ORCID: https://orcid.org/ 0000-0002-6501-7853 \\ Universidade Federal do Piauí, Brasil \\ E-mail: maylaguimaraes@gmail.com
}

\begin{abstract}
Resumo
Objetivo: conhecer os desafios e as possibilidades enfrentadas pelo serviço social no âmbito educacional. Metodologia: Trata-se de revisão narrativa da literatura que teve como questão norteadora: "Quais os desafios e possibilidades do serviço social no cenário educacional?" mediante levantamento bibliográfico nas seguintes bases de dados: Scientific Electronic Library Online (SciELO), Google Acadêmico, além de teses e dissertações do Banco de Teses da CAPES. Desenvolvimento: O serviço social e a educação possuem uma conexão histórica marcada por conflitos, projetos e lutas societárias. No cenário educacional a assistência social atua a favor da democratização do ensino, da permanência, das condições de ingresso e conclusão da trajetória escolar, garantindo o acesso à educação, assistência estudantil e educação inclusiva. Em seu exercício, o assistente social enfrenta múltiplas manifestações da questão social, que se expressam através das desigualdades políticas, econômicas e culturais das classes sociais. Considerações Finais: A inserção do assistente social na educação se torna fundamental, tanto pela existência de demandas concretas quanto pelas possibilidades de intervenção profissional, não apenas na assistência estudantil.

Palavras-chave: Assistentes sociais; Docentes; Ensino; Educação superior.
\end{abstract}

\begin{abstract}
Objective: to know the challenges and possibilities faced by social work in the educational field. Methodology: This is a narrative review of the literature whose guiding question was: "What are the challenges and possibilities of social work in the educational setting?" through bibliographic survey in the following databases: Scientific Electronic Library Online (SciELO), Academic Google, in addition to theses and dissertations from the CAPES Theses Bank. Development: Social service and education have a historical connection marked by conflicts, projects and societal struggles. In the educational scenario, social assistance works in favor of the democratization of education, permanence, conditions for entering and completing the school trajectory, ensuring access to education, student assistance and inclusive education. In their exercise, the social worker faces multiple manifestations of the social issue, which are expressed through the political, economic and cultural inequalities of social classes. Final
\end{abstract}


Considerations: The insertion of the social worker in education becomes fundamental, both because of the existence of concrete demands and because of the possibilities for professional intervention, not just in student assistance.

Keywords: Social workers; Teachers; Teaching; College education.

\begin{abstract}
Resumen
Objetivo: conocer los retos y posibilidades que afronta el trabajo social en el ámbito educativo. Metodología: Se trata de una revisión narrativa de la literatura cuya pregunta rectora fue: "¿Cuáles son los desafíos y posibilidades del trabajo social en el ámbito educativo?" mediante levantamiento bibliográfico en las siguientes bases de datos: Scientific Electronic Library Online (SciELO), Academic Google, así como tesis y disertaciones del Banco de Tesis CAPES. Desarrollo: El servicio social y la educación tienen una conexión histórica marcada por conflictos, proyectos y luchas sociales. En el escenario educativo, la asistencia social trabaja a favor de la democratización de la docencia, la permanencia, las condiciones para el ingreso y culminación de la trayectoria escolar, asegurando el acceso a la educación, la asistencia al estudiante y la educación inclusiva. En su ejercicio, el trabajador social enfrenta múltiples manifestaciones de la problemática social, que se expresan a través de las desigualdades políticas, económicas y culturales de las clases sociales. Consideraciones finales: La inserción del trabajador social en la educación se torna fundamental, tanto por la existencia de demandas concretas como por las posibilidades de intervención profesional, no solo en la asistencia al estudiante.
\end{abstract}

Palabras clave: Trabajadores sociales; Profesores; Enseñando; Educación universitaria.

\title{
1. Introdução
}

Nos últimos anos o âmbito educacional tem se expandido bastante, e ao longo dessa expansão nota-se que as instituições de ensino possuem equipes formadas por vários profissionais, que atuam de forma multidisciplinar no ambiente de ensino. Entre esses profissionais, se destacam os professores, os orientadores pedagógicos, a equipe de gestão, o psicólogo, o fonoaudiólogo e o assistente social (Silva, 2019).

Nesse sentido, o profissional do serviço social é responsável por desenvolver importantes ações nesses ambientes colaborando para uma educação de qualidade, assegurando direitos e proporcionando um espaço de promoção da cidadania e igualdade (Silva, 2019).

A escola é considerada um campo social fundamental, uma vez que é nestes espaços que os alunos demonstram sua realidade social. Portanto, tornou-se necessário a inserção do assistente social à equipe multidisciplinar para trabalhar com outros profissionais, colocando em prática seus conhecimentos teóricos metodológicos e técnico operativo, em inúmeras situações que podem prejudicar o desempenho e aprendizado do aluno como: trabalho infantil, desemprego dos pais, violência doméstica, fome, drogas, alcoolismo, evasão escolar, exclusão social, e outros agravos (Silvestre, 2018).

De acordo com Dentz e Silva (2015) o Serviço Social e a Educação apresentam uma conexão histórica, pois ambos são marcados por conflitos, projetos e lutas societárias. Por isso, possuem uma articulação que deve ser fortalecida, já que a atuação profissional do serviço social em políticas educacionais pode assegurar a garantia de direitos (CFESS, 2012).

Ainda, em seu exercício, o assistente social enfrenta múltiplas manifestações da questão social, que se expressam através das desigualdades políticas, econômicas e culturais das classes sociais (CFESS, 2012).

Nessa perspectiva, a introdução do serviço social na Política de Educação constitui uma possibilidade de favorecer a efetivação do direito à educação através de ações que viabilizem o acesso e a permanência da população na escola, bem como a qualidade dos serviços no sistema educacional (Vieira, 2021).

Nesse contexto, diversas reflexões e discussões evidenciaram a importância deste profissional na assistência de várias demandas existentes nas instituições de ensino. Com isso, o presente estudo tem como objetivo conhecer os desafios e as possibilidades enfrentadas pelo serviço social no âmbito educacional.

\section{Metodologia}

Trata-se de uma revisão narrativa de caráter descritivo com abordagem qualitativa a respeito dos desafios e 
possibilidades do serviço social no cenário educacional. A coleta de dados foi realizada no período de setembro a outubro de 2021, que teve como questão norteadora: "Quais os desafios e possibilidades do serviço social no cenário educacional?"

A revisão narrativa se constitui no mapeamento, na categorização e análise da literatura, permitindo a atualização do conhecimento sobre uma temática e a discussão de determinado assunto sob o ponto de vista teórico ou contextual, bem como a identificação de enfoques, lacunas e perspectivas para estudos futuros (Vosgerau \& Romanowski, 2014).

Cabe entender que a revisão narrativa não exige protocolos rígidos e explícitos de busca e seleção, nem demanda necessidade de esgotamento das fontes (Vosgerau \& Romanowski, 2014).

Ademais, permite conhecer o estado da arte do objeto de estudo e a sua posição histórica, contribuindo para a construção de novas perspectivas sobre o assunto, diferenciando-se da revisão sistemática porquanto não restringe a busca dos estudos a meios muito criteriosos e por utilizar a subjetivação como possibilidade para interpretação dos resultados (Flick, 2009).

Para o levantamento dos estudos, foi realizado a busca de artigos nas bases de dados: Scientific Electronic Library Online (SciELO), Google Acadêmico, além de teses e dissertações do Banco de Teses da CAPES. Para isto, foi adotado os seguintes descritores: assistentes sociais; docentes; ensino e educação superior; bem como seus respectivos escritores no idioma inglês: Social Workers; Faculty; Teaching Education, Higher.

No que se refere a análise dos dados, inicialmente foi feita uma leitura exploratória e seletiva para verificar o conteúdo dos estudos e selecionar as informações de cada um conforme o objetivo desta pesquisa. Em seguida, utilizou-se a técnica de análise temática para aprofundar o conhecimento e para criação de novas abordagens e conceitos inerentes ao trabalho do assistente social que está inserido no ensino superior.

\section{Resultados}

\subsection{Aspectos históricos da educação brasileira}

A educação no Brasil ao longo dos anos foi marcada por avanços, retrocessos, tendências e discussões. Desde o período colonial a educação foi configurada como uma ferramenta de poder e controle, e no sistema vigente tal objetivo se expandiu, uma vez que a educação era utilizada também como meio de comercialização. No entanto, enquanto houveram controvérsias também foi possível notar uma resistência para a melhoria e concretização da mesma (Almeida \& Pereira, 2012).

Logo no início do século XX, o Brasil apresentava uma taxa significativa de analfabetismo, e com isso houve um aumento do número de escolas primárias com a finalidade de aumentar o índice de alfabetização da população (Dentz \& Silva, 2015). No ano de 1920, o Brasil passava por uma fase de grande otimismo pedagógico e entusiasmo geral pela educação. Nesse período, a escola era considerada um dos mais importantes sistemas sociais brasileiros. A escola primária se transformava na principal preocupação de diversos educadores, pois enxergava-se nesta, o meio pelo qual a transformação social poderia tornar-se concreta, verdadeira e efetiva (Gadotti, 2012).

A sociedade brasileira é fortemente capitalista o que acaba gerando inúmeras desigualdades, e com isso as diferenças se transformam em barreiras e os conflitos permanentes. Dessa forma, a educação passa por uma constante luta de interesses entre as classes sociais existentes. Nesse sentido, a educação é transformada num mecanismo que atua com base nos interesses específicos dentro deste sistema capitalista (Viana, 2020).

Nesse contexto, de acordo com Almeida (2011), a política de educação brasileira é marcada pelo enfrentamento das condições da sociedade capitalista. Com isso, uma das táticas de intervenção do estado consiste em procurar assegurar as condições necessárias para a reprodução, que resultem em luta de classes trabalhadoras dando direção aos seus processos de formação. Dessa maneira, partindo das lutas de classes pelos seus direitos sociais, é que se incentiva a produção de consciência própria, isto é, autônoma. Entretanto, compreender a política educacional e toda sua trajetória é recuperar momentos marcantes 
na história de legislações, mudanças institucionais, vínculos com a dinâmica de crises da sociedade do capital, e da realidade de força de trabalho da real situação brasileira.

Ao analisar a educação de forma mais abrangente, nota-se que por meio dela o indivíduo pode apropriar-se de conhecimentos historicamente acumulados pela humanidade, sendo esta, apenas uma das funções da escola. Com isso, através da apropriação destes conhecimentos o indivíduo pode se capacitar para atuar de maneira efetiva no seu meio social, intervindo inicialmente na sua própria realidade (Gadotti, 2012).

Segundo Viana (2020), as desigualdades sociais enfrentadas por diversas famílias brasileiras, constituem aspectos determinantes da obtenção do ensino público ofertado a estas mesmas populações. Portanto, é fundamental a realização de mais investimentos e melhorias significativas na qualidade do ensino público, desde o nível fundamental da educação até o nível superior, principalmente nas regiões onde as desigualdades sociais são demasiadas e preocupantes. No entanto, para que as melhorias sejam efetivadas, é necessário que aja paralelamente, a elaboração e implementação de políticas públicas destinadas ao acesso e à permanência destas populações a este sistema educativo.

A educação moderna vem assumindo um papel cada vez mais significativo no que diz respeito às responsabilidades para com a formação dos estudantes que são acolhidos diariamente nos locais de ensino. Essa condição é formulada por várias questões, determinadas através de fatores que vão desde a cognição, afetividade e desenvolvimento motor a elementos sociais, culturais, éticos e morais (Cruz, Freitas \& Oliveira, 2016).

Nesse contexto, o sistema educacional é associado à uma relação constante de troca de conhecimentos entre os cidadãos que a ele pertencem, gerando em cada um deles potenciais e habilidades variadas. Dessa maneira, a escola precisa estar firmada por um trabalho que obedeça a realidade social, cultural e econômica de seus alunos por meio da proximidade e fortalecimento da relação familiar nesse processo, o qual está para além de um método educacional, podendo ser considerado também uma ordem social, considerando que a formação para a cidadania é uma realidade escolar (Cruz, Freitas \& Oliveira, 2016).

\subsection{Serviço social e as políticas de escolarização}

A relação entre serviço social e educação não é uma questão nova, uma vez que os assistentes sociais, desde sua origem, sempre estiveram à frente na educação, decorrente das contradições das relações Capital x Trabalho. Segundo os autores Dentz e Silva (2015), alguns estudos, apontam a inserção do serviço social nas escolas dos Estados Unidos ao longo do ano de 1906, onde esses profissionais tinham a função de analisar a evasão escolar e construir um elo entre a família, a escola e a comunidade.

Já no Brasil, o serviço social surgiu em meados do ano de 1930. Nesse mesmo período, foi observado as primeiras experiências de assistentes sociais na escola, atuando como um vínculo entre a família e a instituição de ensino (Martinelli, 2011).

Para fazer uma análise e ter mais conhecimento sobre a política e o cenário educacional e, como a presença do serviço social nas instituições de ensino é essencial, faz-se necessário entender como são determinadas as relações, as comunicações e as ações que acontecem no ambiente escolar. Nesse sentido, aponta-se que a escola não é apenas um espaço para aprender e ensinar, mas também um espaço de formação e socialização (Freire, 1996).

De acordo com Gonçalves (2007), é atribuição do serviço social atuar nas relações sociais no que diz respeito à sociabilidade das famílias com baixa renda e cuidados relacionados à moral, procurando adequá-los aos padrões comportamentais ligados aos valores dominantes. A implementação do serviço social nas escolas dos Estados Unidos em 1906, influenciou de forma significativa a prática do serviço social brasileiro, nesse ambiente. Nessa época, o método utilizado era o de serviço social de caso, efetuado com pais e alunos. 
Nesse contexto, a atuação do assistente social era traçada sob um viés individualista e moralista, que procurava ajustar o aluno à ordem social culpando-o pelo estado de pobreza vivenciado, uma vez que não existiam críticas acerca das problemáticas sociais e sua relação com a sociedade. O indivíduo era culpado por sua situação de vulnerabilidade. No cenário educacional não era diferente: questões como evasão escolar, analfabetismo, reprovação e dificuldades de aprendizagem eram relacionadas ao indivíduo e a sua família (Barbosa, 2015).

Segundo Amaro (1997) os educadores e assistentes sociais possuem desafios semelhantes, e encontram na escola um ponto comum para enfrentá-los. Existe uma necessidade de fazer algo para solucionar os problemas sociais que refletem de forma negativa no desempenho do aluno e leva o educador pedagógico a recorrer ao profissional do serviço social.

Nos últimos anos, os assistentes sociais vêm levantando cada vez mais a importância de sua atuação no âmbito educacional, desde a educação infantil até o ensino superior, e estão conquistando inúmeros espaços sócio-ocupacionais. Isso é possível porque este profissional atua diretamente no combate de questões sociais, revelando-se essencial no ambiente educacional cheio de desigualdades e descaso do Estado, no qual é um local de aprendizagem, gerador de relações sociais, políticas e culturais (Piana, 2009).

De acordo com Oliveira (2016), a inclusão dos assistentes sociais nas instituições de ensino é pautada no princípio de que estes profissionais são responsáveis por proporcionar melhores condições de vida e trabalho, motivando nos usuários a consciência de sua valorização humana, além de ser o profissional habilitado para mediar os conflitos entre a escola, a família e a sociedade.

Nessa perspectiva, nota-se que uma das maiores contribuições do serviço social no âmbito educacional é verificar e dar respostas às manifestações da questão social, assegurando a efetivação dos direitos sociais e viabilizando a integração da escola no conjunto da sociedade como um todo. Com isso, o profissional, na figura do assistente social, deve assumir uma conduta crítica, baseando-se no contexto amplo, procurando evitar práticas imediatistas para assim, compreender a realidade complexa na qual está inserido e assumir efetivamente as demandas apresentadas (Amaro, 2017).

Assim como em outros campos de atuação, o cenário educacional é um espaço ideal para atuação profissional do serviço social, uma vez que existem necessidades concretas fruto das manifestações da questão social na educação, além das possibilidades de intervenção profissional na assistência estudantil e em outras demandas. No entanto, existem algumas preocupações consistentes sobre a atuação do assistente social na educação, principalmente, os desafios e as possibilidades do exercício profissional face a esta política pública.

\subsection{Desafios e possibilidades do assistente social na educação}

O serviço social no cenário educacional tem a possibilidade de colaborar com a realização de diagnósticos sociais, apontando possíveis alternativas à problemática social vivida por diversas crianças e adolescentes, o que possibilitará a melhoria das suas condições de enfrentamento da vida escolar (Almeida, 2011). Nesse sentido, o assistente social por ter sua atuação pautada pelo Código de Ética Profissional e na intervenção das expressões da questão social e suas particularidades, ou seja, seus conflitos, adversidades e problemáticas, esse profissional tende a vivenciar inúmeros processos de trabalho. Um dos maiores obstáculos na efetivação do trabalho do assistente social é principalmente o fato de que a solução de vários problemas apresentados ou colocados a este, estão nas mãos de outros profissionais ou órgãos, ou seja, geralmente, a solução de sua ação encontra-se além de sua atuação (Viana, 2020).

Considera-se que o trabalho desenvolvido por assistentes sociais nas instituições de ensino é uma estratégia que pode propiciar condições para o exercício da cidadania, bem como para o protagonismo e inclusão de indivíduos, não apenas no âmbito escolar, mas na sociedade de modo geral. No ambiente escolar, o profissional de serviço social não elabora ações que substituem aquelas desenvolvidas por profissionais tradicionais da área de educação. No entanto, seu trabalho se realiza com o 
objetivo de subsidiar, assistir a escola, e os demais profissionais, no confronto de questões que compõem o roteiro da formação e da ação profissional do assistente social, sobre as quais, na maioria dos casos a escola não sabe como intervir (Cruz et al., 2013).

Nesse sentido, segundo Amaro (2017) o profissional do serviço social pode desempenhar nas instituições educacionais diversas competências inerentes à sua profissão, como por exemplo: analisar a situação social e econômica dos estudantes e de seus familiares; orientar a organização e o funcionamento de instituições que agreguem professores e pais de alunos; instruir as famílias no encaminhamento dos alunos a instituições previdenciárias; executar triagem de alunos que precisam de auxílio para material escolar, transporte, tratamento médico, dentário e etc.; elaborar relatórios e prestar informações sobre suas atividades; realizar a articulação com os grupos da escola (professores, pais) e outras organizações comunitárias; esclarecer e direcionar a família e a comunidade para que assumam seu papel de responsabilidade no processo educativo.

Portanto, esses profissionais são fundamentais no auxílio do processo de formação escolar, gerindo problemas educacionais e também dificuldades de outras esferas que podem surgir nas escolas. O trabalho dos assistentes sociais pode assegurar o bom desempenho dos educandos, sempre em um contexto multidisciplinar e, por esse motivo, coletivo (Vieira, 2021).

Por isso, é necessário enfatizar e propagar o trabalho do serviço social com o intuito de mostrar para a sociedade, além do âmbito escolar, para que a população tenha consciência disso, como também para legitimar e contribuir com a atuação destes profissionais (Vieira, 2021).

O desafio de atuação do serviço social está na luta, juntamente com outras áreas, para uma maior garantia dos direitos educacionais certificados por lei, desde a infância até à velhice, desde a modalidade do ensino infantil até o nível superior, formando um sujeito mais crítico e conhecedor de seus direitos. Tornando o aluno mais atuante politicamente, consciente de suas escolhas e ações na procura por uma emancipação e justiça social. Desse modo, faz-se necessário informar que já existem estratégias na prática, mas, ainda assim, existem desafios muito importantes para o desempenho pleno dos assistentes sociais na política da educação (Almeida, 2011).

Segundo Amaro (2017), esses desafios são baseados no contexto do projeto ético-político do serviço social na educação, que expõe a importância da educação no processo de transformação e emancipação social. Fica evidenciado que esses desafios não podem ser resolvidos enquanto não houver uma conscientização de outras áreas educacionais. É necessário fortalecer as relações entre os assistentes sociais, pedagogos, professores, alunos e família, o que faz com que os desafios se estendam.

Em material elaborado a partir do acúmulo teórico-metodológico, técnico-operativo e ético-político do serviço social que sinaliza a história do serviço social na educação, foi evidenciado que as possibilidades de inserção e atuação do assistente social nas políticas de escolarização se fundamentam social e institucionalmente pelos princípios e fins da educação nacional (CFESS; CRESS, 2011-2014).

No entanto, o profissional do serviço social se encontra submetido a inquestionáveis contradições. Por um lado diversos limites lhe são impostos, e por outro lado as possibilidades normalmente são reduzidas, entretanto, é fundamental que o assistente social realize capacitações, e esteja integrado em movimentos sociais e de sua categoria, examinando a realidade, embasando-se teoricamente, objetivando seu crescimento e fortalecimento profissional, além de estar sempre pronto e qualificado a resolver problemáticas, propondo respostas satisfatórias às demandas que se lhes são apresentadas (Cruz, Freitas \& Oliveira, 2016). 


\section{Considerações Finais}

O desafio de atuação do serviço social está na luta para uma maior garantia dos direitos educacionais assegurados por lei, desde o ensino infantil até o superior. Nessa perspectiva, a contribuição do assistente social no campo educativo é essencial, apresentando-se como um fator determinante na relação família, aluno e escola.

A presença deste profissional nas instituições de ensino pode garantir o bom desempenho dos estudantes, em um contexto interdisciplinar e coletivo. Portanto, é fundamental que novos estudos sejam realizados a fim de ampliar e aprofundar as discussões e a produção de conhecimento sobre essa temática. É necessário ressaltar e propagar o trabalho do serviço social, para que a sociedade, além do ambiente escolar, reconheça a importância das suas ações para legitimar e contribuir com a atuação destes profissionais.

\section{Referências}

Almeida, N. L. T. (2011). Conselho Federal de Serviço Social GT de Educação: Subsídio para o debate sobre serviço social na educação. Recuperado: 10 de outubro de 2021, de CFESS - Conselho Federal de Serviço Social: http://www.cfess.org.br/arquivos/subsidios-servico-social-na-educacao.pdf.

Almeida, N. L. T. \& Pereira, L. D. (2012). Serviço social e educação. Lumen Juris.

Amaro, S. T. A. (1997). Serviço Social na escola: o encontro da realidade com a educação. Sagra Luzzatto.

Amaro, S. (2017). Serviço Social em escolas: fundamentos, processos e desafios. Vozes.

Barbosa, M. Q. (2015). A Demanda Social Pela educação e a Inserção do Serviço Social na Educação Brasileira. Papel Social.

Barros, J. M. \& Silva, E. P. (2017). Desafios e possibilidades de atuação do serviço social na educação do município de Duque de Caxias (RJ). Revista Ciência Contemporânea, 2 (1), 127-147.

CFESS. Conselho Federal de Serviço Social. (2012). A inserção do Serviço Social na Política de Educação na perspectiva do Conjunto CFESS/CRESS: elementos históricos e desafios para a categoria profissional. Revista Serviço Social, 14 (30), 244-258. org/10.26512/ser_social.v14i30.12989

CFESS. Conselho Federal de Serviço Social; CRESS - Conselho Regional de Serviço Social. (2011-2014). Subsídios para atuação de Assistentes sociais na política de educação: CFESS/CRESS, 2011-2014. Recuperado: 05 de outubro de 2021, de CFESS - Conselho Federal de Serviço Social: http://www.cfess.org.br/arquivos/BROCHURACFESS_SUBSIDIOS-AS-EDUCACAO.pdf.

Cruz, T. O. S., Santana, E. F., Pontes, J. O. et al. (2013). Uma análise sobre a atuação do/a assistente social na educação: notas para o debate. In: VI Jornada Internacional de Políticas Públicas, São Luís (MA). Anais: Eixo 15 - Impasses e desafios das políticas de educação, pp. 1-9.

Cruz, T. S., Freitas, P. H. S. \& Oliveira, J. L. (2016). Assistentes sociais na escola: reflexões sobre as contribuições do serviço social para a educação. Socializando, 3 (1), pp. 69-77.

Dentz, M. V. \& Silva, R. R. D. (2015). Dimensões históricas das relações entre educação e Serviço Social. Revista Serviço Social \& Sociedade, 121 , pp. 7-31. org/10.1590/0101-6628.011.

Dentz, M. V. \& Silva, R. R. D. (2017). Estratégias de intervenção do serviço social nas políticas de escolarização: uma análise contemporânea. Educação e Pesquisa, 43 (3), 695-710. org/10.1590/s1517-9702201702152155.

Flick, U. (2009). Introdução à pesquisa qualitativa. Trad.: Joice Elias Costa. (3a ed.), Artmed.

Freire, P. (1996). Pedagogia da autonomia: saberes necessários à prática educativa.: Paz e Terra.

Gadotti, M. (2012). Educação popular, educação social, educação comunitária: conceitos e práticas diversas, cimentadas por uma causa comum. Revista Dialogos, 18 (1), 10-32.

Gonçalves, A. B. (2009). A Prática Cotidiana do Assistente Social na Escola Privada. (Dissertação inédita de Mestrado em Serviço Social e Política Social). Universidade Estadual de Londrina, Londrina.

Iamamoto, M. V. (2005). O Serviço Social na contemporaneidade: trabalho profissional e formação profissional. Cortez.

Lessa, S. E. C. (2013). A educação contemporânea, o combate à pobreza e as demandas para o trabalho do assistente social: contribuições para este debate. Serviço Social e Sociedade, 113, 106-130.

Martinelli, M. L. (2011). Serviço Social: Identidade e Alienação. (16a ed.), Cortez.

Oliveira, L. R. Serviço Social na Educação: Uma Reflexão sobre a Importância da Inclusão do Assistente Social nas Escolas. Recuperado: 29 de setembro de 2021, de Fundação Telefônica Vivo: https://fundacaotelefonicavivo.org.br/noticias/servico-social-na-educacao-uma-reflexao-sobre-a-importancia-da-inclusaodo-assistente-social-nas-escolas/.

Piana, M. C. (2009). Serviço Social e Educação: olhas que se entrecruzam. Serviço Social \& Realidade, 18 (2), $182-206$. 
Research, Society and Development, v. 10, n. 14, e276101422167, 2021

(CC BY 4.0) | ISSN 2525-3409 | DOI: http://dx.doi.org/10.33448/rsd-v10i14.22167

Santana, A. M. (2019). Educação socioambiental: uma perspectiva a partir da inserção do (a) assistente social na escola. Interfaces Científicas - Humanas e Sociais, 7 (3), 9-20.

Silva, L. R. (2019). A contribuição do serviço social na inclusão de pessoas com deficiência no ensino regular: uma experiência em Campos dos Goytacazes/RJ. (Trabalho de Conclusão de Curso em Bacharelado em Serviço Social). Universidade Federal Fluminense, Campos dos Goytacazes.

Silvestre, L. P. F. (2018). Políticas Públicas no Brasil: Exploração e Diagnóstico. 6. Ponta Grossa - PR: Ed. Atena.

Viana, T. M. N. (2020). Serviço social na educação desafios e possibilidades do exercício profissional em experiências do Tocantins. (Trabalho de Conclusão de Curso em Bacharelado em Serviço Social). Universidade Federal do Tocantins, Miracema do Tocantins.

Vieira, P. L. C. (2021). A Importância do Serviço Social nas Políticas de Educação. Recuperado: 29 de setembro de 2021, de Conteúdo Jurídico, Brasília-DF: https://conteudojuridico.com.br/consulta/artigos/56247/a-importncia-do-servio-social-nas-polticas-de-educao.

Vosgerau, D. S. A. R. \& Romanowski, J. P. (2014). Estudos de revisão: implicações conceituais e metodológicas. Diálogo Educacional, 14 (41), $165-189$. 